\title{
Akurojin-no-hi: Construction of an Urban Legend
}

\author{
John Livingston \\ University of Florida
}

Faculty Mentor: Ann Wehmeyer, Department of Languages, Literatures \& Cultures

\begin{abstract}
Akurojin-no-hi is a flamelike ghost in Japanese folklore that was thought to appear in Mie Prefecture, Japan. Little information is known about this creature other than its basic physical characteristics and that it appears on rainy nights. Through utilization of translated primary and secondary sources, including literature, and historical scientific data, from Japan as well as analysis of older documents from between the $17^{\text {th }}$ and $19^{\text {th }}$ century, this paper aims to draw connections between natural disasters, and economic factors that occurred during the Edo Period of Japan. I consider all these elements and describe how they influenced the conceptualization of Akurojin-no-hi. I begin by observing the economic developments of the period and then connect these new developments to other events also occurring in Japan at the time, such as the long journeys of the Shikoku Pilgrims who traveled along wide, expansive roads like the Tokaido. I then discuss some of the natural disasters which occurred during the Edo Period, mainly the large, widespread fires which affected cities both big and small, and then explain how these fires influenced the conceptualization of the Akurojin-no-hi as a response to people's understanding of historical and sociogeographical events at the time. Finally, I compare the characteristics of the Akurojinno-hi to the characteristics of other yokai and analyze their differences and similarities.
\end{abstract}

Keywords: Akurojin-no-hi, Edo period,

\section{Introduction}

The Akurojin-no-hi is a flame-like ghost that became popular during the Edo period and was said to appear on rainy nights, where those who make contact with it become extremely ill. Akurojin-no-hi is one of many supernatural beings, referred to in Japanese folklore as yokai (妖 怪). There are many different types of yokai, including demons, spirits, and monsters. Yokai come to be popularized as a result of a number of different situations and circumstances. As noted by Michael Dylan Foster (2015), yokai myths, or stories about yokai, are the result of things we can't easily explain and form as a result of how people "explain occurrences that don't easily fit our everyday understanding of the way things work" (pp. 15-16). Yokai myths are rarely created from one individual incident but arise from many different events, such as the phenomenon associated with Akurojin-no-hi. The Edo period of Japan (1603-1868) was a period 
of rapid change and monumental events. This period was characterized by the expanding of roads, greater volume of travel, and the shifting of the economy, as well as the large number of natural disasters which were prevalent at the time. This paper examines the development of Akurojin-no-hi as an urban legend that arose in response to the numerous natural disasters at the time, economic expansion and outlines the ways in which these factors contributed to the creation of Akurojin-no-hi.

\section{Natural Disasters}

During the Edo period, there were a multitude of disasters that transformed economic activity and travel across the country, such as fires and earthquakes. Historically, disasters have arguably been one of the strongest factors that lead to the creation of both yokai and urban legends. Alongside urban legends, art and culture have also often been influenced by natural disasters. A good example of a creature whose creation was influenced by disasters of the Edo period is 悪路 神の火 (Akurojin-no-hi, literally, fire of the god of the bad road). The Akurojin-no-hi is a flamelike creature that "moves around like a lantern on rainy nights, and should you encounter its flames, you will fall ill with an epidemic sickness." (Shigeru, 1996, pg. 25). The flame characteristics of the Akurojin-no-hi could be linked to the rampant fire disasters which were prevalent throughout the Edo period, such as one of the 49 fires which toppled the city of Edo over a 268 year period (Kuroki, 1999, p. 3). These fires were not limited to just big cities, they also occurred in smaller towns and villages that could be found along the road. Kito (2012) outlines the huge effects these fires, such as the great fire of Meireki in 1657, had on the economic development of the city of Edo. As Kito explains, the great fire had a profound effect on the landscape of the city of Edo:

until the Great Kanto earthquake many years later, [it] was one of the three biggest fires up to that time, the others being the great fire of London in 1666 and the gigantic fire which nearly eradicated Rome in 64 A.D. After this fire, the city of Edo took preventative measures for fires, like expanding the roads and moving the locations of buildings, such as the feudal lords' residences and temples, as well as creating more empty space. The use of thatched hut roofing was also prohibited, and buildings in the city were renovated with tile roofs and clay walls. Fire-fighting facilities under the direct control of the Tokugawa shogunate were established. During this time, Edo continued to expand. For the sake of the revival and enlargement of Edo, the Tokugawa shogunate spent a vast amount of money. The reserves accumulated since Ieyasu were diminished, and the shogunate's finances headed towards bankruptcy (p. 92). 
This widespread fire was one of many in Edo that demonstrated both the impact it had on the thought process of citizens at the time, through policy and development. The development of Japan and the traveled roads during this period coincided with these new measures put in place to prevent fires. Akurojin-no-hi's conception happened inside of a society which was fearful of and attempting to prevent further flames. Despite the efforts by the Tokugawa Shogunate, these fires continued and had a negative impact on the economy.

Another, similar example of this type of influence from natural disasters is the Ansei great earthquake of 1855 and how this tragedy “shook the political and social consciousness of Edo's residents during the final decades of the Tokugawa period" (Smits, 2006, p. 1045), and resulted in the creation of namazu (lit. "catfish" in Japanese) imagery in protective talismans, at the time. Charateristics of the earthquake, as well as influences from cultural and economic events, were featured in the imagery associated with the catfish creature. Gregory Smits, a historian of Japanese history observes some of these connections in his paper Shaking up Japan: Edo Society and the 1855 Catfish Picture Prints. Smits notes in his paper "natural disaster often serves as a catalyst, accelerating and bringing to the fore problems, contradictions, and tensions below the apparently calm surface of society." (p.1045). Smits also identifies a number of key underlying issues in society at the time, including famines, and food shortages due to farmers shirking their duties and passing through different areas on pilgrimage. In their journeys, such pilgrims "often became unruly as they passed through towns and villages." (p.1046). In addition, Smits analyzes the arrival of Commodore Matthew Perry in 1853, just two years prior to the earthquake, stating that "the people of Edo did not view the earthquake of 1855 as a random event. Instead, they understood it within a context of other recent earthquakes and recent political events, especially the visits of Commodore Matthew Perry in 1853 and 1854." (p.1046). Over time, the perception of these natural disasters, which occurred during the years before the earthquakes, (1830-1855) changed. The Tokugawa Shogunate eventually started to attribute these disasters more to cosmic powers and "as this divergence between cosmic moral principles and the state of government increased, strange atmospheric phenomena, crop failures, epidemics, earthquakes, and other natural disasters became the concrete manifestations of cosmic 'displeasure"” (Smits, 2006, p. 1047). This cosmic way of thinking lead many to change how they perceived the disasters around them, such as being the fault of a deity or god. The Earthquakes which followed other disasters, were thought by many to be caused by a large subterranean catfish, who is normally 
contained underground by a foundation stone at Kashima Shrine, which is guarded by the Kashima deity. This association of the catfish prints to the earthquakes was hardly novel and did not occur merely as a result of the earthquake alone; protective talismans proliferated shortly thereafter. Merchants created these talismans as a response to the earthquakes, as "fear of further damage generated talismanic namazue-e, many of which featured an image of the Kashima deity re-asserting control over the earthquake namazu (with a dragon-like tail) with a sword." (Smits, 2006, p.1052). It was thought that if one put these talismans outside their house it would aid in keeping the catfish under control and prevent future earthquakes from occurring. It is unlikely that, without this newfound 'cosmic' mindset, that societies reaction to the earthquakes would have been so superstitious. These observations by Smits help demonstrate the effect prolonged issues can have on the characteristics and societal perception of myths like the namazu catfish. There was no single event that influenced the conception of the namazu prints, but it was sum of many different cultural, social and economic factors.

\section{Economic Influence}

The economic influence that these fires had on the Tokugawa shogunate is one example of how the fires placed a strain on not just the local economies of villages which burned down, but also the overarching economy of Japan at the time. These large fires are one of several factors which influenced how people perceived their surroundings, not just those living in the city, but also those traveling along the roads and visiting different towns.

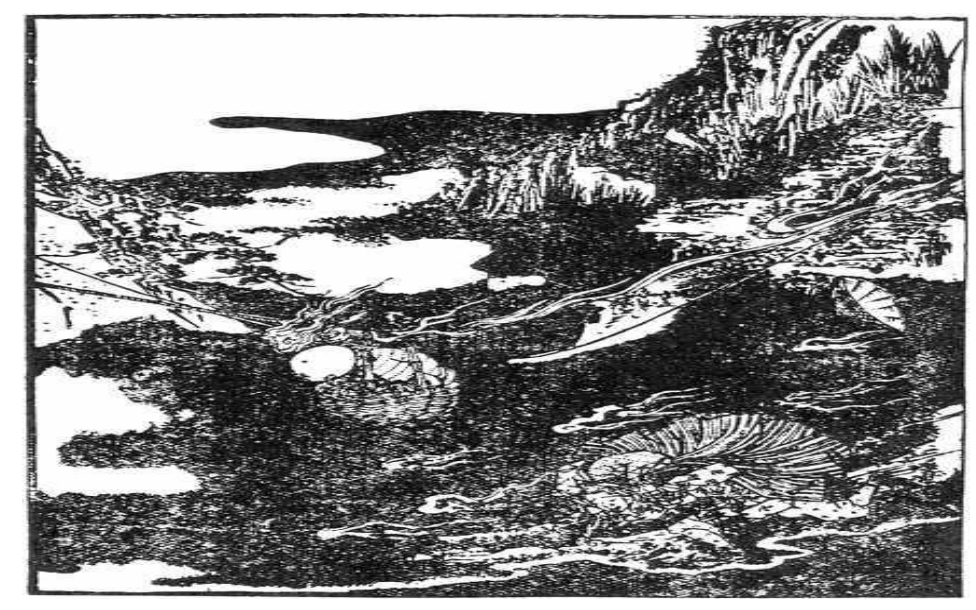

Figure 1. Illustration of Akurojin-no-hi, from Kansō sadan (閑空頊談) by Sadatake Sasaki (pen name, Tamenaga Shunsui) (1790-1843). Illustrator: Tagawa Kuninao, and others 
Economic conditions factor strongly in the creations of urban legends in many cultures, and the creation of Akurojin-no-hi is no exception. The increasing volume of economic growth and an increased amount of travel during the Edo period led to the creation of stories of yokai along the roads being traveled, such as how the Akurojin-no-hi was claimed to be seen in Mie prefecture, which was close to the Tokaido, one in a network of highly traversed highways that the central government in Edo controlled. The traffic strongly shaped the culture, economics, society, and religions of the day. Edo period Japan saw rapid development in the nation's economy. The road system around Japan vastly expanded in response to the widening trade networks and the introduction of the alternate attendance system by the Tokugawa-run government, which required daimyo ${ }^{1}$ to travel back and forth between the capital of Edo on every other year, in part to limit their ability to foment independent rebellions. Alternate attendance stimulated the economy and "with foreign trade largely restricted by political fiat, alternate attendance functioned as a powerful economic stimulant: the very considerable expenses involved in participation in the system - including transport and travel services, the construction and repair of a network of compounds in Edo, and the maintenance of support staffs there-spread those expenditures along the highways, as well as in Edo and the domains" (Vaporis, 1997, p.26). Based on alleged sightings, those who encountered the Akurojin-no-hi were likely merchants, and travelers. Due to this being a highly traveled road it would make sense that there would be individuals who claimed to encounter this creature. However, despite the somewhat high volume of the roads, only certain individuals were allowed to travel and needed special permission, such as merchants and daimyo who were traveling to and from the capital. Those who were not given such permission likely took more roundabout, and possibly dangerous paths to their destination. The Akuro (悪路)in Akurojin-no-hi simply means “bad road", and is a creature that is said to appear on difficult to traverse paths. Many of these paths were subject to the effects of harsh climate and weather.

\section{Atsmopsheric Conditions}

The way people in a country perceive their surroundings can be heavily influenced by the weather, and weather certainly played a sizable role in the development of Akurojin-no-hi. The alleged sightings of Akurojin-no-hi are said to occur on rainy nights and the roads that individuals claimed to encounter it on were said to be treacherous. According to a paper by Hirofumi Katahira, which details different kinds of natural disasters and their association with 
the seasons during historical eras of Japan, during the Edo period of Japan, the number and types of natural disasters varied depending on the time of year. Katahira provides a graph and discussion to illustrate which types of disasters occurred with greater and lesser frequency in particular months:

That is to say, natural disasters which surged after the last third of the month of May continued to increase for a while, and approached their peak from late June to early July. Judging from the fact that the frequency of natural disasters, such as floods and epidemics, were high around this time, it is thought that there is a close connection between these kinds of disasters and the rainy season in Japan. The second peak, which is normally around late July to early August and right after the rainy season, has atmosphere temperatures which are extremely high and the midsummer sun continues to shine for long periods of time. There are many misfortunes, such as droughts and water shortages, that stand out around this time which support these statistics. (Katahira, 2006, pg. 4)

While this paper gives a sample size pertaining to Kyoto, it still gives a good idea of the kind of findings by Katahira, such as the fact that the rainy season has a fewer amount of fires. Even though there being fewer fires may seem like a contradiction, the rainy season being associated with sickness makes sense in the context of Akurojin-no-hi, a creature that causes those who happen to catch sight of become sick on rainy nights. Interestingly, according to the data from Katahira's study regarding the rainy season in Tokyo during the Edo period, while the number of fires were down, the overall amount of natural disasters were up during this time. A higher amount of natural disasters, such as tumbled trees and heavy rain, were also associated with the rainy season. These kinds of natural disasters are the kind that can lead to obstructed, hard to traverse paths along roads. These are the same kind of hard to traverse roads that are described during alleged encounters of Akurojin-no-hi. 


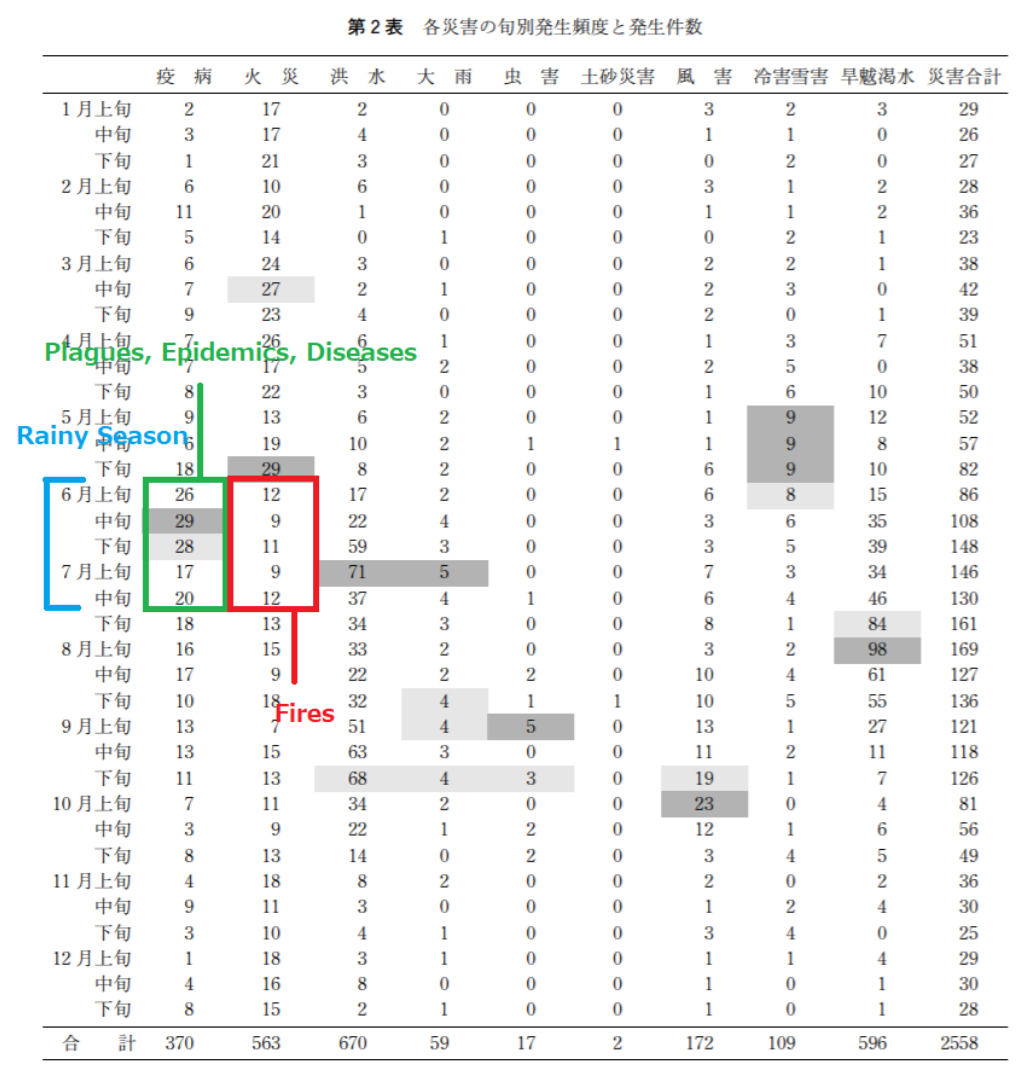

Figure 2. Chart depicting the types of plagues common around the Edo period (horizontal, top) and their frequency depending on the month (vertical, left). (Katahira, 2006, pg. 3) colored annotations and highlights provided by author

\section{Presence of Yokai}

Culturally, the Edo period was considered 'The golden age of yokai', with many artists, such as Toriyama Sekien, who would travel around Japan looking for yokai and concepts of yokai to fill their encyclopedias. The creation and research in the field of yokai was at its height during the Edo period and sometimes drew the attention of even popular artists such as Sekien, who despite being a master artist, is generally only remembered for his yokai bestiaries. (Yoda, 2017, pg. 8). Through authors and artists like Sekien, there were many illustrations and information being created and circulated about yokai. The giant boom in yokai research, alongside the rise in natural disasters created a steep upsurge in the documentation and illustration of yokai. One example of a yokai that became popular around the time of Sekien's yokai book (Gazu hyakki yagyō “Illustrated Night Parade of a Hundred Demons;, 1776) is the Hidarugami (ヒダル神), which is a yokai that appears on the road at night that confronts travelers and overwhelms them with a sense of strong hunger and pain. Much like the Akurojin-no-hi, "those who come into 
contact with the Akurojin-no-hi become sick and fall ill." (Megumi, 1994). The hidarugami are said to be the spirits of former travelers who starved to death, and if someone is killed by a hidarugami they join the hidarugami horde. These kinds of yokai seem to have been influenced by the turmoil travelers experienced on the roads, such as the traveling Shikoku pilgrims. There is also another yokai referred to as Shichinin Dogyo (七人同行), which is a group of seven pilgrims traveling along the road and those who encounter it "die as a result." (Yokai Database). This group of yokai greatly resemble the common image of traveling Shikoku pilgrims, and carry the same kind of walking stick, kongō-jo (金剛杖) and wear the same kind of hat, sugegasa (菅笠).

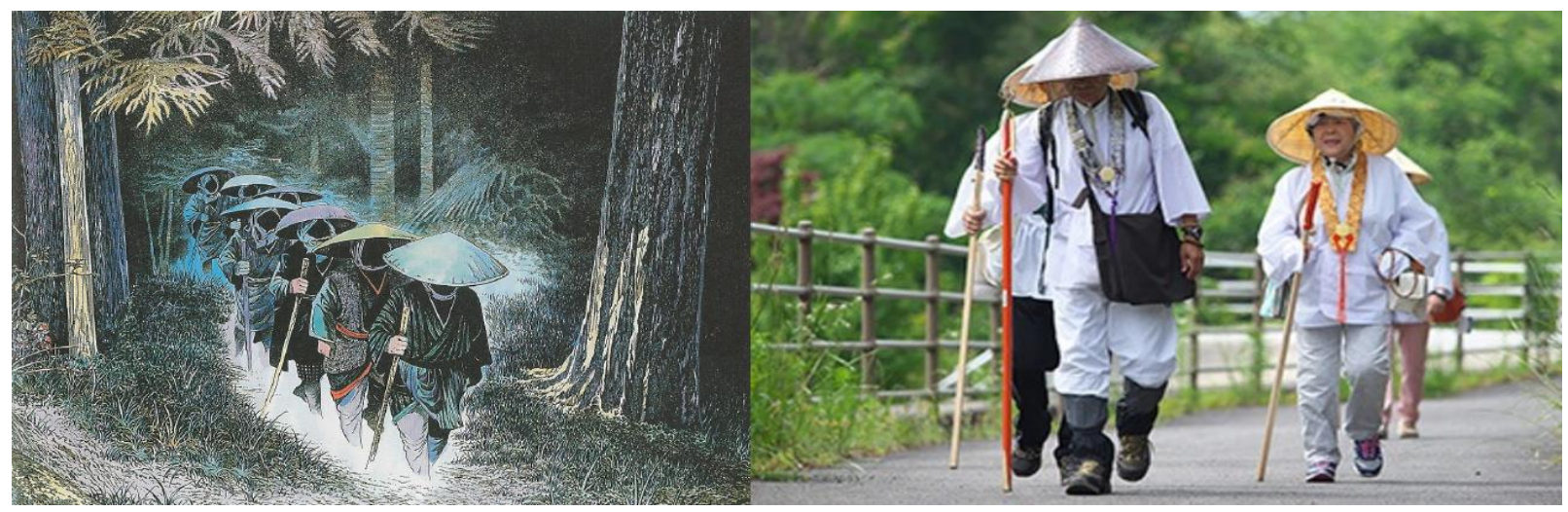

Figure 3. Shichinin Dogyo (Pictured left) and a group of traveling Shikoku pilgrims (right). Images combined together by author. Source(s): (Left image: Illustration by Shigeru, Mizuki) (Right image: https://www.gov-online.go.jp/eng/publicity/book/hlj/html/201606/201606_12_en.html)

Another important factor regarding yokai development in the public mind is the context of the person who claims to have seen it, how they were traveling, and where their destination was. As cited earlier from Smits, the events prior to a yokai becoming popularized, are as important as the event itself, and one big event prior to the story of the Akurojin-no-hi was the mass migration of people, particularly pilgrims, along the Tokaido Road to Ise Grand Shrine. Pilgrimages during the Edo period were one of the few ways to bypass the harsh restrictions against travel during the Edo period (Nenzi, 2006, p. 77), which generally only permitted merchants and those of high status to travel, and because of this it is likely that many of those who witnessed the horrible fires of the Edo period were those claiming to be traveling for religious purposes, or selling their 
goods. As mentioned above, one type of person who could often be found on the road during the Edo period was the Shikoku pilgrim. The Shikoku pilgrim would often be a young runaway and have very little access to funds or money. (Nenzi, 2006, p. 79) Coincidentally there were instances where "pilgrims were mostly merchants" (Nenzi, 2006, p. 77), so while merchants and pilgrims were two of the biggest groups of people traveling the road, there were circumstances in which an individual was both traveling with the purpose of selling goods and making a religious pilgrimage to Ise shrine. Among these pilgrims and merchants who traveled, many were poor, broke the law and had to turn to unfortunate measures to be able to survive, as "mass pilgrimages almost inevitably involved begging on the part of the pious travelers" (Nenzi, 2006, p. 78). While the economy certainly boomed during the Edo period, events like mass travel had a negative economic impact which influenced the local economy and citizens, as "the unannounced departures of the runaway devotees, far from being uniformly accepted and condoned as commendable acts of faith, often stirred up controversy at home, where employers, landlords and family members resented the disruption of economic balance brought about by the disappearance of employees, tenants and co-workers" (Nenzi, 2006, p. 81), and in fact "following the Mass pilgrimage of 1771 and the widespread government fiscal reforms of the 1790s, local authorities took notice of the financial repercussions of such phenomena and acted accordingly, curtailing some of the exemptions they had historically granted to religious travel." (Nenzi, 2006, p. 81). Around the time of these pilgrimages, many people became sick, and many disasters were occurring, including rampant fires. The sickness these pilgrims experienced along the roads was probably one example of the kind of illnesses people related to Akurojin-no-hi. Those passing through the Tokaido around this time most likely saw many of the fiery disasters in the towns and areas they passed through. Pairing these observations of the fiery incidents, along with the economic and health trials they faced during these times sheds some light on why the alleged Akurojin-no-hi sightings were described the way they were. These fire attribute disasters likely inspired the flame characteristics of Akurojin-no-hi, while the sickness that the travelers along the road felt was probably an influential factor in the creation of the instant sickness someone would feel when coming into contact with the Akurojin-no-hi.

\section{Modern Day Interpretations}

While there is not much information available in recent publications, many modern day versions of the Akurojin-no-hi legend can be found on many different blogs and online forums. 
Most blogs that discuss Akurojin-no-hi are in Japanese, but some can be found in English, such as one from someone under the pseudonym "Dr.Yokai", who claims that when he was a child his mother would tell him about Akurojin-no-hi and the dangers involved, saying that when he was young he and his family often took car trips and "would drive through very sharp mountain roads, which winded and twisted and were perilously steep." (Akurojin no Hi, Mie Prefecture's Roadside Phenomena, 2012). These "steep roads" are similar to the "treacherous paths" described in tales of the Akurojin-no-hi. There are also modern day retellings of Akurojin-no-hi which are still passed around, such as one by an online writer who goes by Ainonai jinja (相内神 社), who claims to be employed at a shrine and wrote a modern day retelling of the legend of Akurojin-no-hi. This legend also employs travelers on a road, but involves samurais traveling instead of merchants and while they nearly come into contact with Akurojin-no-hi, they narrowly manage to avoid it. The legend ends with the samurai giving the same descriptions of the Akurojin-no-hi that other tales from the past also stated, that it appears on dark, rainy nights, and it has a fiery appearance. These consistent interpretations reinforce the connections of travel and danger, as well as the way in which citizens at the time interacted with the changing environment of Japan in the Edo period, and even today. The changing landscape was a catalyst for the development of Akurojin-no-hi and similar yokai.

\section{Similar Yokai and Their Connections}

There are a large number of yokai that are said to have flame-like characteristics. Akurojinno-hi is described as simply a flame-like creature with no distinct human-like characteristics. Much like the catfish prints (namazu), there is also influence from the living world which affected the creation of Akurojin-no-hi. As previously mentioned, the influence for the Akurojinno-hi, which stems from the real world, is almost certainly the flames from many of the disasters during the Edo period, and is also perhaps something thought to be controlled by another deity.

The name 'Akurojin-no-hi' in translation literally means "fire of the god of the bad road", but there is also another yokai, simply called “Akurojin” ( 悪路神) ( god of the bad road). Stories surrounding this yokai include descriptions such as "on the night of the Tsushima Shrine Festival (June 14th), a flame which resembles a mass of 33,000 torches leaps from the festival ship and enters the shrine. After that a dreadful, epidemical god also appears. That night, everyone tightly 
locks their doors and windows and a deafening silence falls over the town. The heavenly god Gozu is said to oversee Akurojin.” (Nakashio, 1965, p. 63). The god Akurojin is said to appear after a large number of flames, which would lead one to guess that the flames that precede Akurojin are possibly the "Akurojin-no-hi" itself. The god Akurojin is described as an "epidemical god" and plague spreads wherever it goes, and like Akurojin-no-hi, people actively avoid it to prevent getting sick. Tsushima Shrine is a shrine located within Tsushima, Aichi Prefecture, near a large body of water and is separated from what is now Mie prefecture (previously an array of provinces, including Ise). The long road along the gulf between the shrine was traveled by many pilgrims and merchants. Tsushima Shrine is also along the path from Edo (now Tokyo) to Ise Shrine, which many pilgrims traveled along during the Edo period. Edo was one of the main locations where fires broke out spurratically, so pilgrims who had seen these disasters traveled long distances between shrines with those types of experiences. Both Akurojin and Akurojin-no-hi are said to appear in areas where there is a religious presence, and also have similar attributes associated with them. Despite the distance between Tsushima Shrine and Mie Prefecture, the new networking of roads and mass migration of merchants and pilgrims allowed these ideas to extend to other places. The similarities between these two different yokai demonstrate how fire influenced the conception of not just Akruojin-no-hi, but other yokai like Akurojin, aided by the spread of information and travel afforded at the time.

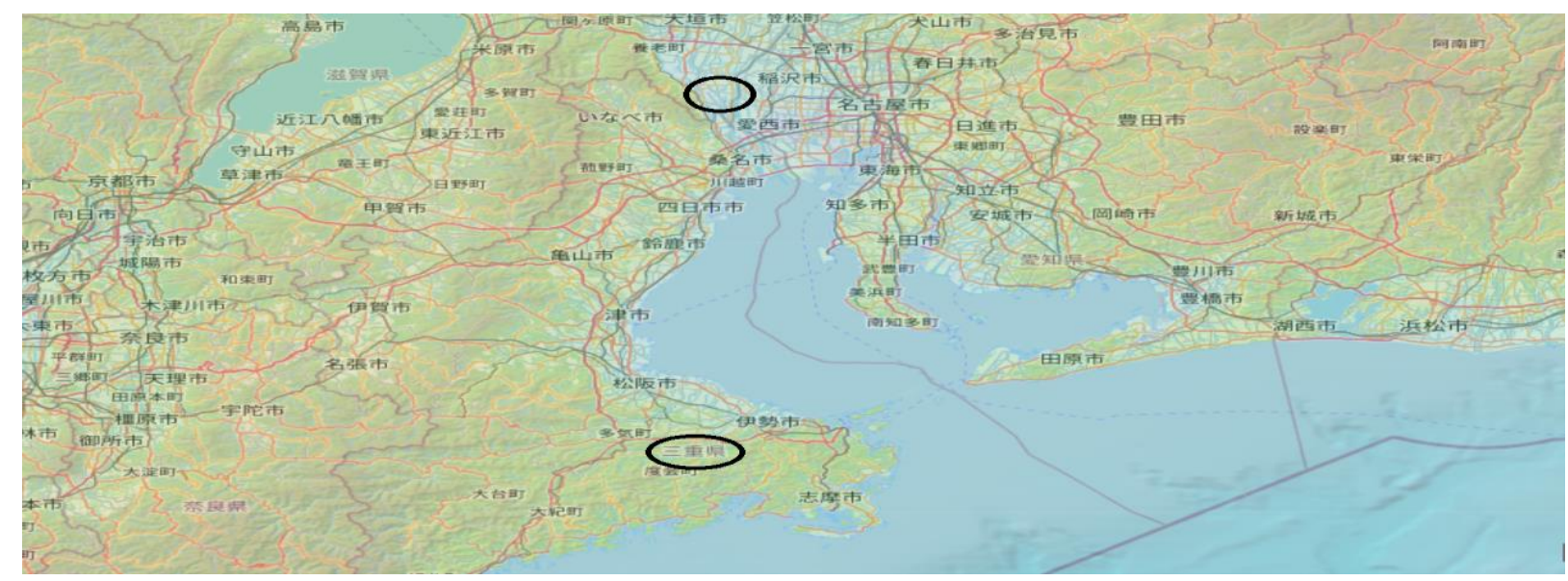

Figure 4. Map displaying the location of Tsushima Shrine (upper circle) and Mie Prefecture (lower circle) relative to each other. Source: Mukashi Mappu (昔マップ) (Circled locations added by author) 


\section{Conclusion}

When first analyzing a yokai like Akurojin-no-hi, it may be perplexing how a yokai with such a limited amount of characteristics came to conception. While not as popular as it was in the past, the Akurojin-no-hi myth still has a legacy that can be seen in newer versions of these stories, such as online stories like One-hundred Tales: Night 37 Akurojin-no-Hi (Ainonai Jinja). Analyzation of similar instances, like Namazu, further demonstrate the psychological impact these natural disasters had. Cultural influence from the citizens at the time, including shikoku pilgrims and merchants provided a lens through which this type of yokai could be viewed, its inception being a product of the time. The natural disasters and changing landscape of the Edo period created an environment which allowed for the creation of a yokai like Akurojin-no-hi. Like many other urban legends and yokai, this study has made the case for the creation of the Akurojin-no-hi myth to be the result of a number of social, economic, and cultural factors. The impression Akurojin-no-hi left was not just a result of these factors, but also how all these elements were interpreted by Japanese society during the Edo period. Further investigation into Akurojin-no-hi may involve analyzing its connection to other yokai and how religion played a part in its inception.

\section{References}

Foster, M. D. (2015). The Book of Yōkai : Mysterious Creatures of Japanese Folklore. . Oakland, CA: University of California Press.

Fredrick, Cranes (2016) Disasters of the Edo Period(江戸の災害, edo no saigai) Tokyo, Japan: Kodansha (Kodansha Gendaishisho).

Jinja, Ainonai. (2019) One-hundred Tales: Night 37 Akurojin-no-Hi (百物語:第 37 夜 悪路人の火, hyaku monogatari: dai 37 yo Akurojin-no-hi) https://kakuyomu.jp/works/1177354054890392552/episodes/1177354054890607325

Katahira, Hirofumi. (2006) Disasters in Historical Kyoto and their Seasonality. (京都における歴史時代の 災害とその季節性, Kyoto ni okeru rekishi jidai no saigai to sono kisetsusei) Kyoto, History of Natural Disasters Research Institute

Kito, Hiroshi. (2012) Developing Circumstances •Edo (環境先進国・江戸, kankyou senshinkoku•edo) Japan: Yoshikawa Kobunkan.

Kuroki, Kyō (1999). Fires of Edo (江戸の火事, edo no kaji) Japan: Dōseisha. 
Megumi, Asami (1994). Summarized Records of Drug Acquisition in Various Provinces (諸州採薬記抄 録, Shoshuu Saiyakuki Shouroku), In Plant Hunting Japan: Kagaku Shoin

Michifumi, Isoda. (2017) Japanese Advancements Born from the Tokugawa period (徳川がつくた先進国 日本, tokugawa ga tsukutta senshinkoku nihon) Tokyo, Japan: Bungeishunju.

Morita, Kenji. (2019) Inside the lifestyle of the Edo Period (江戸暮らしの内側) Japan: Chuoukouronshinsha,

Nakashio, Kiyoomi. (1965) Process Analysis of Transforming Narratives - Revolving Around Asonuma Kitan (説話変容の工程分析一阿曽沼綺譚を回転軸にして, setsuwa henyou no koutei bunseki asonuki kitan wo kaitenjiku ni shite), In Oral Literature Study (伝承文学研究, denshoubungaku kenkyuu). Japan: Denshou Bungaku

Nenzi, Laura. "To Ise at All Costs: Religious and Economic Implications of Early Modern

Nukemairi." Japanese Journal of Religious Studies 33, no. 1 (2006): 75-114. Accessed January 4, 2020. www.jstor.org/stable/30233793.

Shigeru, M. (1998) Shichinin Dōgyō - The Seven Pilgrims, illustration from Mujara

Shigeru, Mizuki (1996) The Big Illustrated Yokai Encylopedia (妖怪大図鑑, Yokai Daizukan) Japan: Kodansha

Smits, Gregory Shaking up Japan: Edo Society and the 1855 Catfish Picture Prints Journal of Social History, Vol. 39, No.4 (Summer, 2006), pp. 1045-1078

Tamenaga, Shunsui (1790-1843). A Leisurely Perspective on Complicated Topics (閑空頊談, Kanso sadan). tōkyōfu : bankyūkaku

Tanaka, S. (2016). Shikoku Pilgrims on Pilgrimage . Retrieved from https://www.govonline.go.jp/eng/publicity/book/hlj/html/201606/201606_12_en.html

Vaporis, C. (1997). To Edo and Back: Alternate Attendance and Japanese Culture incthe Early Modern Period. Journal of Japanese Studies, 23(1), 25-67. doi:10.2307/133123

Yoda, Hiroko. (2017) Japandemonium Illustrated: The Yokai Encyclopedias of Toriyama Sekien. New York: Dover Publications

\section{Endnotes}

${ }^{1}$ A daimyo was a feudal lord who ruled large areas of Japan from the 12th century to the 19th century and during the Edo period of Japan (1600-1868), daimyo were under the control of the Tokugawa Shogunate. 